Research Article

Jan Výtisk, Vladimír Kočí, Stanislav Honus*, and Mojmír Vrtek

\title{
Current options in the life cycle assessment of additive manufacturing products
}

https://doi.org/10.1515/eng-2019-0073

Received Sep 10, 2019; accepted Sep 16, 2019

\begin{abstract}
Additive manufacturing (AM) is a manufacturing process that allows for the creation of a physical object from a digital model. Additive manufacturing has a number of advantages over the conventional methods, inter alia the production of very complex machinery components, and a lower consumption of raw materials. Thanks to these advantages, the technology has been booming recently. The paper compares the advantages and disadvantages of additive technologies in the context of environmental impacts using Life Cycle Assessment (LCA). The paper describes the most important aspects of additive manufacturing, reviews the basic principles and phases of LCA method, including its application in AM, and outlines selected publications dealing with LCA and additive technologies. In conclusion, we recommend the most suitable methodologies to assess environmental impacts of additive technologies. To be specific, LCA is suitable to assess $\mathrm{AM}$ as for the material and energy flows, and in general, research in this field is considered highly promising.
\end{abstract}

Keywords: Additive Manufacturing, Energy and Mass Flow, Life Cycle Analysis, Life Cycle Assessment

\footnotetext{
*Corresponding Author: Stanislav Honus: VŠB - Technical University of Ostrava, Faculty of Mechanical Engineering, Department of Energy Engineering, 17. listopadu 2172/15, 70800 Ostrava - Poruba, Czech Republic; VŠB - Technical University of Ostrava, Centre ENET, 17. listopadu 2172/15, 70800 Ostrava - Poruba, Czech Republic; Email: stanislav.honus@vsb.cz

Jan Výtisk, Mojmur Vrtek: VŠB - Technical University of Ostrava, Faculty of Mechanical Engineering, Department of Energy Engineering, 17. listopadu 2172/15, 70800 Ostrava - Poruba, Czech Republic Vladimur Kočı: VŠB - Technical University of Ostrava, Faculty of Mechanical Engineering, Department of Energy Engineering, 17. listopadu 2172/15, 70800 Ostrava - Poruba, Czech Republic; University of Chemistry and Technology, Prague, Faculty of Environmental Technology, Department of Environmental Chemistry, Technická 5, Dejvice, 16628 Praha 6, Czech Republic
}

¿ Open Access. (C) 2019 J. Výtisk et al., published by De Gruyter. (cc) BY License

\section{Introduction}

Additive manufacturing is also well known under the terms of 3D printing technology, or Rapid Prototyping. It is a manufacturing process that makes an instant physical three-dimensional object from a digital model. The virtual 3D model of a component is made using computeraided design (CAD) software or with 3D scanning, and it is "sliced" into thin layers that provide the path code for the 3D printing tool. Next, the printing tool, subject to certain specifications, implements a specific process to re-create the model into the physical form layer by layer till a finished object is printed [1].

The start of 3D printing technology date back to the second half of the 20th century. The first inventor related to 3D printing was a Japanese researcher Hideo Kodama, who came up with a modern approach of layering in stereolithography using ultra-violet radiation through joining light-sensitive polymers in the early 1980s. Nevertheless, the term of stereolithography was attributed to Chuck Hull, who had patented the process in 1984. Recently, this manufacturing method has spread rapidly, having been launched by many industrial enterprises worldwide (United States, United Kingdom, Sweden, Germany, Israel, etc.) [2]. It is predominantly popular in the sectors of aerospace, medical \& dental, and automotive industries, as well as power and gas, food, and textile industries. Although the expected market with rapid prototyping should exceed $\$ 20.2$ billion by 2020 , rapid manufacturing is to grow much more [3]. Figure 1 gives sales percentages in the different sectors in 2014, which points at a wide spectrum of applications of the technology [4]. Worldwide, for the last 25 years the AM industry has increased from $\$ 295$ million to $\$ 5.1$ billion, under an annual rate of $25.4 \%$ [5]. An even more aggressive growth is expected, namely to $\$ 230$ 550 billion by 2025 [6], where the primary market of $\$ 100$ 300 billion will be consumer goods, and \$100-200 billion will be products in the medical/ dental and aerospace industries.

Among interesting studies dealing with additive technologies there are 3D-printed heart from human cells [7], program IBUMA - Intelligent burner manufacturing from 


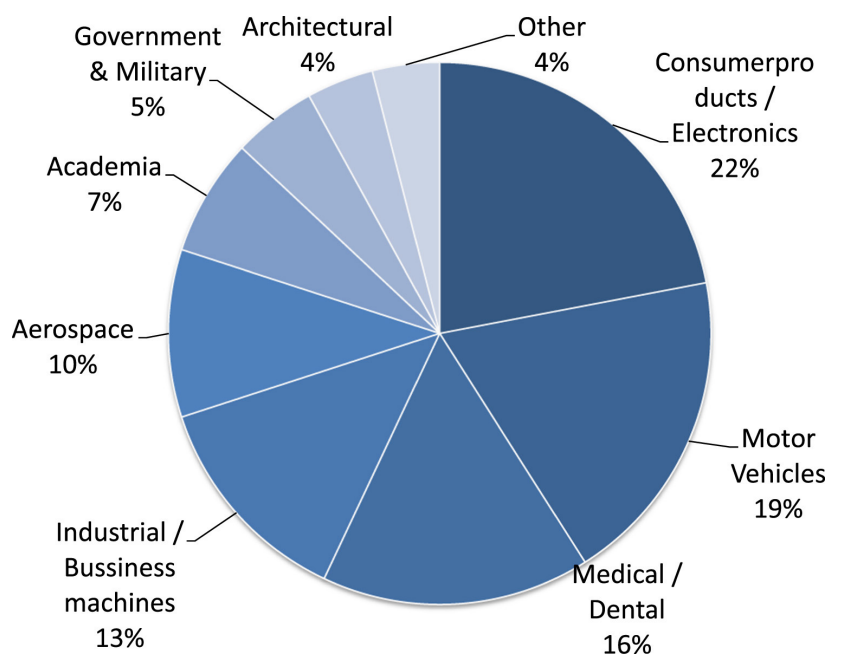

Figure 1: Distribution of AM revenues over business sectors showing the widespread application [4]

Siemens's division in Finspång, Sweden [8], or gas turbines blades SGT -400 by Siemens [9]. Among currently presented development projects there is a turboprop engine (Catalyst) by GE Aviation, where one third of the engine will be printed using several types of metal. It is stated that the original number of 855 discrete components will be replaced by mere 12 components [10]. Next, there is a program HITEMMP (High-Intensity Thermal Exchange through Materials and Manufacturing Processes) for ultraperformance heat exchangers carried out by GE Research in cooperation with the University of Maryland and Oak Ridge National Laboratory, or a joint project IDAM (Industralization and Digitization of Additive Manufacturing) of BMW Group, the Fraunhofer Institute for Laser Technology ILT and RWTH Aachen University focusing on mass manufacturing of structural optimized differential housing [11].

The results of the above mentioned studies as well as of many others imply a number of advantages, but also challenges for further development. In general, we can claim that the advantages are complexity and design freedom, customization, single step manufacturing, lead time reduction, risk mitigation, ease of access, and, last but not least, sustainability and costs. On the other hand, there is still space for innovation, such as enlargement of the printer's working space and thus creation of larger components, an increase in the speed of sintering process - rapid tooling, powder specification, final quality of the surfacelayer thickness, or competitive production cost. These areas are naturally interlinked and fall in the categories of materials, making, metrology and market [12] - see Figure 2.

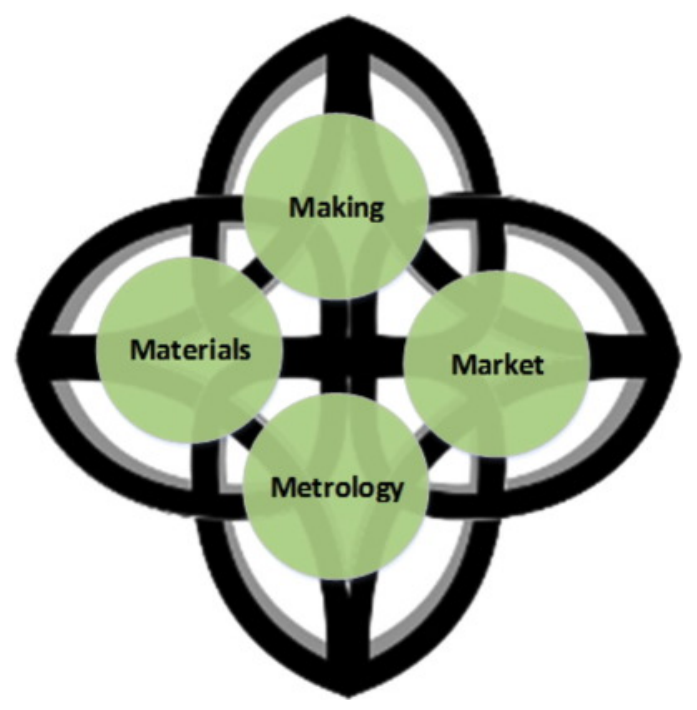

Figure 2: The four M's of AM [12]

The major energy transfer in additive technology is the energy transfer through radiation, which occurs between the laser's head and the reinforced material. This phenomenon is referred to as energy transfer via electromagnetic radiation. Another essential energy consumer or energy transfer is heating and cooling in many AM technologies. For example, in manufacturing Binder Jetting use binders that require a relatively lower amount of heat. However, it is important to select binders that are applicable and durable, which may be a critical point. AM is a process making use of non-equilibrium solidification, and thus it is very important to understand material sustainability as for the limiting working conditions of the given technology. The importance of hot and cold working, heat treatment and surface finish can be critical for metallic parts and are of a major concern in load-bearing and/ or high repetitive cycle applications [12]. Figure 3 compares the specific energy requirement along with the production speed and the achievable resolution for the different AM technologies [13]. Considering the 17 Sustainable Development Goals and 169 Targets listed in 2030 Agenda [14], industrial sustainability was reviewed to include both ecoefficiency as well as eco-effectiveness [15]. Although these topics are subjects of intensive research, achieving better efficacies need not be always be sufficient, especially due to growing urbanized population and absolute limits of Earth's sustainability [16].

In the past decades, emphasis has been placed on the assessment of potential anthropological impacts, which also concerns the development of new technologies. As any other manufacturing process, additive manufacturing has environmental aspects that may, in contrast to conven- 


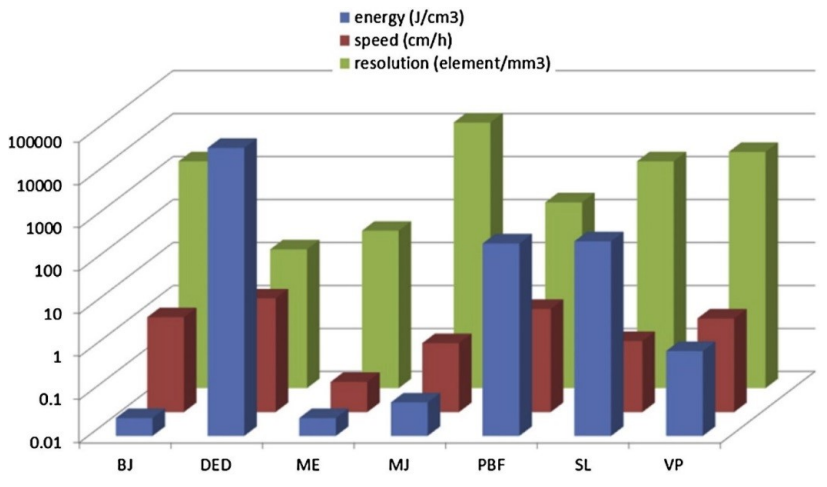

Figure 3: Relative energy use compared to the speed and resolution of fabrication in different AM technologies [13]

tional technologies, bring certain benefits and savings to the environment, but may also represent strain. In a simple comparison with conventional production techniques, additive technologies are less demanding in feedstock raw materials as less scrap is produced during manufacturing. However, they may be technologies of higher energy intensity. The assessment of potential environmental impacts of additive manufacturing cannot be based on the assessment of any single phase of the technology, but we must consider as wide technological context as possible, from raw material extraction, via production material manufacturing, service life of the final products as well as environmental impact assessment related to the produced waste. Therefore, to balance advantages and disadvantages of additive technologies in the context of environmental impacts, it is important to assess additive technologies in a complex manner, i.e. as for their overall life cycle [17].

Life Cycle Assessment - LCA is used to assess technologies as well as different products taking into account their life cycles. It is a standardized method [18], which allows not only to compare the given technologies as for their life cycle phases, but also to assess a wide spectrum of potential environmental impacts, including the intensity of consumed material and energy raw materials [19]. The standardized LCA method is used for a wide range of products and manufacturing processes $[20,21]$.

\section{Principles of LCA}

It is an analytical method assessing environmental performance of products based on environmental impacts (material and energy flows) which a system under assessment exchanges with the surroundings, i.e. the environment. An important benefit of the method is the description of environmental impacts using the so-called impact cate- gories [18]. The impact categories are specific environmental problems in which anthropogenic activities participate as a consequence of exchange of substances and energy with the environment [22]. Among the most applied impact categories there are, for example, global warming, decrease in stratospheric ozone, eutrophication, or the formation of photooxidants. The assessment of environmental impacts in LCA is not limited to a list of the different harmful material or energy flows, but using values corresponding to the impact level of the given category provides information on potential specific damage [23].

A complete life cycle of a product starts with the recovery of essential renewable and non-renewable raw materials and sources of energy from the environment. This is to speak about the extraction of ore, crude oil, and exploitation of water resources. In the phase of material production, raw materials are converted into materials to be used further in the manufacturing, usually making use of fuels, electric energy, and other resources. Another phase is the product manufacturing, which consists of the conversion of materials vital for the product manufacturing, of production, assembly of a product, and its packaging to be distributed to the customer. In this phase, the product is consumed/ used, i.e. it fulfils the function it was produced for. The consumer phase also includes energy and raw material requirements (inputs and outputs) for the product transport, repairs, maintenance, or storage. In the instant a consumer does not use a product anymore and does not intend to keep it, the phase of disposal follows. This brings energy and material flows related to the disposal, re-use, or recycling. Through recycling, a certain amount of materials may be recovered to be reused, or they may be used to recover energy [24]. The overall life cycle also includes energy and material flows for transport, e.g. transport of raw materials from the site of extraction to the site of their processing, product transport to the consumer or transport related to product disposal, which implies certain environmental impacts.

In the different life cycle stages, a product interacts with the environment in many ways. Each stage represents a different environmental strain. If we are supposed to compare and evaluate the environmental impacts of technologies, it is important to consider all the life cycle stages and refrain from preferring only some. The major and minor material and energy flows may be equally important from the environmental impact perspective, and thus must be included into the product system. The incorporation of auxiliary flows into the environmental impact assessment is one of the central ideas of LCA [25].

Keeping in mind that each process may include auxiliary flows both at the input as well as at the output, we may 
model the overall product system. When modelling this, we usually use a basic scheme plane which includes processes immediately participating in the life cycle of a product and possibly other scheme planes involving processes related to side flows. In the major product system, each of the process represents an operation participating in the flows of materials or energy running through the product system. The majority of the processes contain other auxiliary flows of materials or energy, and have its own inputs and outputs [26].

\subsection{LCA phases}

LCA comprises four fundamental phases: 1) goal and scope definition; 2) life cycle inventory; 3) life cycle impact assessment; and 4) interpretation of life cycle [18] - see Figure 4 [27]. In the goal and scope definition we describe the basic format of the study, define a functional unit, and choose the method for environmental impact assessment. The life cycle inventory is meant to gather information on the processes participating in the product system. Taking the life cycle inventory, data on the different processes are collected, followed by taking an inventory of inputs and outputs of the whole system and its surroundings. The goal of life cycle inventory is to identify and quantify all the elementary flows related to the product system. There are three basic types of inventories based on their extent, namely 'Cradle-to-grave', 'Cradle-to-gate', and 'Gateto-gate'. In the life cycle inventory phase the clearest principle of modelling is 'Cradle-to-grave'. There are the following steps: plotting a flowchart of the product system, data collection and calculation of a product's ecovector that is the output of the inventory analysis [28]. The ecovector is a set of data representing the amount of different substance emissions into the environment and the intensity of the product system on the raw material resources. This set of data is called an environmental profile and serves to calculate the environmental impacts that are presented as numbers, i.e. results of impact category indicators. Environmental impacts are understood as comparable consequences of environmental aspects on the quality of the environment, human health, and quantity of abiotic or biotic raw material reserves. Life cycle impact assessment is an application of the product's ecovector into the resulting values of impact category indicators. The first step of impact assessment is classification, and attribution of results from the inventory to the different impact categories. The following characterization serves to quantify the level of elementary flow influence on the impact categories. The output is a set of impact category indicator results of spe-

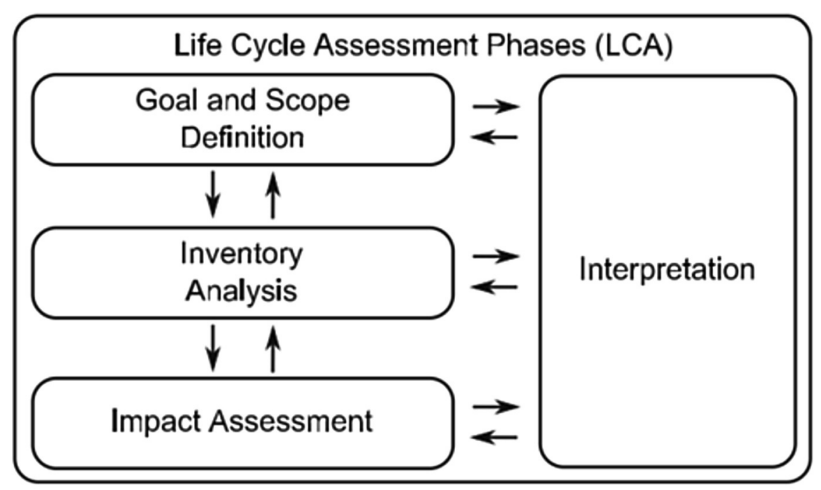

Figure 4: General frame of Life Cycle Assessment [27]

cific values with clearly defined units. The final phase of LCA studies is the interpretation of the findings and identification of significant issues.

\subsection{Midpoint and endpoint indicators of environmental impacts}

To decide which product is safer for the environment, it is important to assess not only the quantity of emitted substances, but also enumerate the specific environmental damage. Various substances are known to have harmful effects, while the intensity of the harm afflicted differs. Life cycle impact assessment thus focuses on the size of the environmental impacts related to the elementary flows and their sums (Kočí 2012).

To better understand the difference between two types of impact category indicators, it is important to explain what the LCA methodology means by midpoint and endpoint indicators [29]. In case we use a reference substance to assess the harmfulness of a given elementary flow, and we relate the capacity of the given elementary flow to cause environmental damage to the selected reference substance, it is midpoint assessment. A midpoint indicator of impact category serves to measure harmful properties of elementary flows, i.e. potential responsibility for the impact category [26]. An example of a midpoint indicator is global warming potential (GWP), which expresses the capacity of greenhouse gas, e.g. methane, to withhold energy in the atmosphere in comparison with a reference substance - carbon dioxide.

The presence of a certain elementary flow in the environment may cause various types of unfavourable effects that manifest as environmental impacts. The term 'endpoint' is understood as final measurable effects observable as environmental damage, which were caused by a sequence of chemical-physical phenomena related to the el- 
ementary flows. The endpoint indicator of an impact category is a quantifiable or quantitative (also in the economic sense) value of certain phenomena brought about in the environment. An example of endpoint assessment in the impact category of global warming is a rise in the ocean's level, glacier melting, frequency of extreme atmospheric phenomena, or spread of sites with malaria incidence.

\subsection{Midpoint and endpoint impact categories}

In practice, there are various characterization models, even for identical impact categories. This is grounded in the fact that the environmental impacts of the elementary flows may be evaluated using diverse indicators. The difference between characterization on the level of midpoint or endpoint can be illustrated on the example of eutrophication impact category. The midpoint indicator of eutrophication impact category is the equivalent amount of bioavailable phosphorus or nitrogen, or a loss of oxygen due to extreme microbial activity. An endpoint indicator may be a decrease in the biological species in the locality (lower biodiversity). Based on which impact category indicator may be used for the characterization, we distinguish characterization at the level of midpoints or endpoints. The influence of different substances on the identical impact categories may be characterized differently. Therefore, it is not possible to mutually compare the results of characterization of impact categories from different characterization models. Based on the selection of impact category indicator, we distinguish midpoint impact categories or endpoint impact categories.

Although the midpoint characterization models do not enumerate real environmental damage and their results are more difficult to interpret for the real environment, they have a more robust natural-science basis. These are characterization models based on as most exactly measurable properties of elementary flows as possible. These characterization models express the level of elementary flow action based on the characteristics that they have in common and that are decisive for their influence on the given impact category [22]. A clearly defined and measurable relationship between the elementary flow and the indicator of impact category serves a rather exact enumeration of impacts of the elementary flows on the impact category. The level of elementary flow influence is thus expressed as an equivalent amount of the given reference substance, e.g. $\mathrm{kg}$ of $\mathrm{CO}_{2}$ equivalent.

The endpoint characterization models aim to describe the relationship between the elementary flow and the final manifestation of environmental damage to be enumerated. For such description and enumeration, endpoint indicators of impact categories are used. In the endpoint characterization models, the level of impact category damage is expressed according to the specific observable environmental damage. The environmental mechanism serving as basis for the methods is grounded either in a natural basis, or may be expressed using economic values, e.g. as a drop in financial revenues. An advantage of the characterization models is an option to merge the results of the impacts of many elementary flows into a lower number of impact categories. The results of the characterization models are more understandable for the wide public. An established index, such as ecological footprint, or ecoindicator, is used as a category indicator. The major disadvantage of the models is a high level of uncertainty given by the fact that the models assume a considerable simplification of rather complex environmental phenomena.

There are many methods used to characterize the elementary flows as for their capacity to participate in the development of an impact category. Some methods are midpoint, others are endpoint, and some combine both approaches [30]. The characterization factors are based on different relationships, where some strictly issue from chemical-physical or biological facts, while others take into account economic or social aspects. ISO standards that describe the LCA methodology [18] do not directly state which characterization model should be chosen. For this reason, we used the concept of a recommended set of characterization methods considering the fact that the most suitable method will always be selected for the given LCA study.

A number of characterization methods are grounded in an extended methodology labelled as CML - Centrum voor Milieuwetenschappen Leiden [23, 31]. It is a midpoint approach which is often used for LCA in Europe. The geographical area of North-American continent is known for the TRACI midpoint methodology [32]. With regard to the differences in the ecosystem composition of a region, the methodology is not suitable for Europe. The first solely endpoint approach is Eco-indicator 99 [33] focusing no longer on the size of midpoints, but on the enumeration of real environmental damage. This way, it is often referred to as 'damage oriented' or 'top-down'. Another damage oriented approach is EPS 2000 [34] expressing the environmental damage in a monetary manner. Another endpoint approach is used in Ecofactor methodology [35]. This one expresses environmental interference of product systems in units corresponding to the shift in environmental conditions towards a selected limit or critical value. An approach combining both midpoint and endpoint impact cat- 
egories is IMPACT 2002+ [36]. This approach has reacted to practical problems of joint characterization of local and global impact categories. Another important methodology is EDIP 2003 [37, 38], which details the concept of localization of environmental impacts and use of various characterization factors for same elementary flows although emitted in different regions. Other methodologies exist and are further developed to assess environmental impacts on other geographic regions, for example a Japanese LIME methodology [39] and Canadian LUCAS methodology [40]. These LCIA approaches often closely build on previous methodologies, mostly CML, Eco-Indicator 99, and IMPACT 2002+, and develop or combine the different characterization models. Recently, ReCiPe approach has been rather popular [41, 42], the framework of which is able to enumerate potential environmental impacts on a wide spectrum of impact categories, both on the midpoint and endpoint level.

Why are there so many different LCIA methodologies? It is caused by the diversity of potential environmental impacts caused by human action and diverse authors' systems of values looking at the impacts, or in general, the value of the environment. Although different characterization models and thus also the methodologies prefer other assumptions or relations, we cannot judge which is better or more correct. It is more practicable to start from the contractor who orders the LCA study and choose a suitable model for a particular purpose. If practicable, it is possible to recommend impact assessment using several characterization models and compare the results. Next, an analysis of the study's sensitivity to the choice of characterization model can be carried out. The development of the different characterization models is not finite and we can expect the introduction of new models that are likely to be grounded in the established models taking into account new environmental impacts.

\section{LCA applied to additive manufacturing}

What methods for environmental impact assessment of additive technologies should be used considering the overall life cycle? Currently, there are several methods that help to express environmental impacts either on the midpoint or endpoint level. Among the most widespread methods there is CML, Ecoindicator 99, and Impact 2002+ [23]. However, more recently, the ReCiPe method [41, 42] has been popular. ReCiPe provides characterization factors for a wide spectrum of elementary flows even for a wide group of different environmental impacts [42]. ReCiPe is also able to express environmental impacts both at the midpoint and endpoint level. The following section refers to some publications dealing with LCA method to assess additive technologies.

Binder-Jetting additive technology was assessed using LCA method and Umberto software [43]. Although the study only dealt with material and energy inputs and outputs, the authors recommended conducting full life cycle assessment [43]. Similarly, the concept of life cycle was used to compare the demands of additive technology and injection moulding in terms of the quantity of materials and energy [44], but the final environmental impacts were not stated. A recommendation to carry out LCA of additive technologies in order to identify potential environmental risks appeared in [45]. Although the authors detail the choice of processes that should be included into the system framework, they are not specific about the environmental impact categories to be used for assessment.

The authors of another study [46] focused on the metallic additive manufacturing of a gear pointing at the fact that the use of plastics is more environmentally sound when using additive technologies. To determine potential environmental impacts the authors used selected impact categories from the CML methodology [23]. The impact categories were: global warming potential (GWP); acidification potential (AP); eutrophication potential (EP); ozone depletion potential (ODP); photochemical ozone creation potential (POCP), and abiotic depletion potential (ADP). The additive technology of laser fabrication appeared to be more environmentally intense when compared with the traditional manufacturing process due to a higher energy intensity of the additive technology [46].

[47] examined the conditions in the environmental impact assessment, namely different measurement methods and the evaluation of environmental impacts, including life-cycle analysis, environmental impact scoring system (EISS), and design for environment (DFE). They concluded that due to insufficient research and rapid development of the technology, many of the problems are still left open.

As a simple and direct application of LCA method need not be suitable to compare the environmental impacts of additive and subtractive technologies, [17] recommend a specific group of environmental criteria. The authors build on CML model [23] and extend it with a joint assessment of Cumulative Exergy Demand, which expresses the energy demands of an assessed product. In the study, the additive technology is evaluated as more environmentally sound [17].

Additive manufacturing may be successfully used to make mold cores for CFRP [48]. In another LCA study, ad- 
ditive manufacturing is compared with conventional manufacturing procedures and ReCipe Midpoint $\mathrm{H}$ is used to assess the potential environmental impacts [41]. The results obtained from SimaPro software do not imply a clear assessment pointing at lower environmental impacts of additive manufacturing. In some impact categories (terrestrial acidification, particulate matter formation, land transformation, metal depletion) additive manufacturing manifests significantly lower demands than conventional processes. On the contrary, in other impact categories, additive manufacturing has higher environmental impacts (freshwater and marine eutrophication). However, a clear trend of the various categories was not observed [48]. ReCiPe on the endpoint level was used to compare additive manufacturing and traditional computer numerical control (CNC) milling machine [49]. The LCA approach was approved and the authors recommend it for the assessment of a wide spectrum of environmental impact categories.

Mold core production using additive technology was assessed using LCA in [50]. The authors did not deal with potential environmental impacts using impact categories, but solely focused on material and energy flows and financial costs.

[51] focused on environmental impacts of laser-based AM compared with conventional production of tools and instrumentation. The authors presented three case studies dealing with quantitative estimates of energy consumption and emitted pollution. They found that laser-based remanufacturing of tooling is most likely to lower environmental impacts and production costs.

The issue of environmental impacts of additive technologies in the building industry was discussed in a study by [52]. They point at the fact that a functional unit must be well chosen for a purposeful application of LCA in the building industry. In their study, they assessed the environmental impacts of three products: brick walls, fibrereinforced concrete slab floors, and roofing materials. To assess the environmental impacts of additive technologies they recommend the ReCiPe midpoint $(\mathrm{H})$ variant. The authors conclude with an advantage of additive technologies due to savings in the materials and thus related decrease in environmental impacts.

Additive technologies also permit optimisations in logistics through reducing the transported quantities over long distances. This way, lower final environmental impacts may be caused - see [53]. Another example is of production and distribution of a plastic eyeglass frame using LCA to assess the environmental impacts of the different systems. They used CML for the environmental impact assessment [23]. The sphere of logistics is closely related to the use of additive technologies in transport and transport industry. The use of eco-efficiency assessment of additive technologies of 3D printing was reported in [54]. They used a unified method to assess material and energy inputs and outputs along with life cycle costing.

\section{Conclusion}

Nowadays, we cannot simply use only the economic perspective to compare different technologies, the output of which is an identical product, as the product's life cycle may generate undesirable externalities at different stages. The externalities are usually difficult to value economically as they have a synergetic character reaching across more areas and often have a negative social impact. Aiming at a complex comparison of production technologies, it is important to include such externalities, such as environmental impacts, into the assessment.

It also holds true when comparing additive technologies either with the conventional and dominating manufacturing procedures as well as comparing the discrete additive technologies with one another. In line with the expected boom in additive technologies, we may also assume improvements in the LCA methods providing more objective assessments.

At present, to evaluate the environmental impacts of additive technologies, recommended may be the current version of LCA methodology ReCiPe [42]. When making the environmental impact assessment, all impact categories should be considered, no environmental impact should be a priori excluded or preferred. Among the key impact categories of additive technologies there is carbon footprint, depletion of material and fossil resources, and particulate matter formation.

Acknowledgement: The paper has been done in connection with project Innovative and additive manufacturing technology - New technological solutions for $3 D$ printing of metals and composite materials, reg. no. CZ.02.1.01/0.0/0.0/17_049/0008407 financed by Structural Foundsof Europe Union

\section{References}

[1] Zhang J., Jung Y.G. (Eds.), Additive manufacturing: materials, processes, quantifications and applications, 2018, ButterworthHeinemann

[2] US Department of Energy, Quadrennial technology review 2015 - Chapter 6: Innovating clean energy technologies in advanced 
manufacturing, 2015, Washington, DC.: US DOE

[3] Wohlers T. (Ed.), Wohlers Report 2012: Executive summary, 2012, Fort Collins: Wohlers Associates Inc.

[4] Wohlers T. (Ed.), Wohlers Report 2014: Additive manufacturing and 3D printing state of the industry: Annual worldwide progress report, 2014, Fort Collins: Wohlers Associates Inc.

[5] Wohlers T. (Ed.), Wohlers Report 2016: Executive summary, 2016, Fort Collins: Wohlers Associates Inc.

[6] McKinsey G.I., Disruptive technologies: Advances that will transform life, business and the global economy, 2013, Seoul: McKinsey Global Institute \& Company

[7] Noor N., et al., 3D printing of personalized thick and perfusable cardiac patches and hearts, Advanced Science, 2019, 1900344

[8] Walachowicz F., et al., Comparative energy, resource and recycling lifecycle analysis of the industrial repair process of gas turbine burners using conventional machining and additive manufacturing, Journal of Industrial Ecology, 2017, 21(S1), 203-215

[9] Liu K., et al., Effect of change in fuel compositions and heating value on ignition and performance for Siemens SGT-400 dry low emission combustion system, Journal of Engineering for Gas Turbines and Power, 2014, 136(3), 031203

[10] https://3dprint.com/209048/ge-catalyst-engine-3d-printparts/ (06/08/2019)

[11] https://additivenews.com/industry/ (06/08/2019)

[12] Tofail Syed A.M., et al., Additive manufacturing: scientific and technological challenges, market uptake and opportunities, Materials Today, 2018, 21(1), 22-37

[13] Lee J.Y., An J., Chua Ch.K., Fundamentals and applications of 3D printing for novel materials, Applied Materials Today, 2017, 7, 120-133

[14] United Nations, Transforming our world: The 2030 agenda for sustainable development 2015, sustainabledevelopment.un.org.

[15] Hauschild M., Better-but is it good enought? On the need to consider both eco-efficiency and eco-effectiveness to gauge industrial sustainability, Procedia CIRP, 2015, 29, 1-7

[16] Kara S., Hauschild M., Herrmann C., Target-driven life cycle engineering: Staying within the planetary boundaries, Procedia CIRP, 2018, 69, 3-10

[17] Paris H., Mokhtarian H., Coatanea E., Museau M., Ituarte I.F., Comparative environmental impacts of additive and subtractive manufacturing technologies, Cirp Annals-Manufacturing Technology, 2016, 65(1), 29-32

[18] ISO 14040 Environmental management- Life cycle assessment Principles and Framework. Geneva, Switzerland, International Organization of Standardization, 2006

[19] Finkbeiner M., Inaba A., Tan R.B.H., Christiansen K., Kluppel H.J., The new international standards for life cycle assessment: ISO 14040 and ISO 14044, International Journal of Life Cycle Assessment, 2006, 11(2), 80-85

[20] Klopffer W., The critical review of life cycle assessment studies according to ISO 14040 and 14044, International Journal of Life Cycle Assessment, 2012, 17(9), 1087-1093

[21] Pryshlakivsky J., Searcy C., Fifteen years of ISO 14040: a review. Journal of Cleaner Production, 2013, 57, 115-123

[22] Kočí V., Posuzování životního cyklu Life Cycle Assessment - LCA, 2019, Chrudim: Vodní zdroje Ekomonitor

[23] Guinée J., Handbook on life cycle assessment - Operational guide to the ISO standards. International Journal of Life Cycle Assessment, 2001, 6(5), 255-255
[24] Fava J.A., Life-Cycle Assessment - a new way of thinking, Environmental Toxicology and Chemistry, 1994, 13(6), 853-854

[25] Weissman A.B., Life-Cycle Assessment, Issues in Science and Technology, 1994, 11(1), 18-18

[26] Kočí V., Na LCA založené srovnání environmentálních dopadů obnovitelných zdrojů energie, 2012, Praha: ECO trend Research centre

[27] Rebitzer G., et al., Life cycle assessment: Part 1: Framework, goal and scope definition, inventory analysis, and applications, Environment international, 2004, 30(5), 701-720

[28] Sonnemann G., Castells F., Schuhmacher M., Hauschild M., Integrated life-cycle and risk assessment for industrial processes, The International Journal of Life Cycle Assessment, 2004, 9(3), 206-207

[29] Bare J.C., Hofstetter P., Pennington D.W., de Haes H.A.U., Life cycle impact assessment workshop summary midpoints versus endpoints: The sacrifices and benefits, International Journal of Life Cycle Assessment, 2000, 5(6), 319-326

[30] Dreyer L.C., Niemann A.L., Hauschild M.Z., Comparison of three different LCIA methods: EDIP97, CML2001 and Eco-indicator 99 Does it matter which one you choose?, International Journal of Life Cycle Assessment, 2003, 8(4), 191-200

[31] Heijungs R., Guinée J.B., Huppes G., Lankreijer R.M., de Haes H.A.U., Wegener Sleeswijk A., Ansems A.M.M., Eggels P.G., van Duin R., de Goede H.P., Environmental life cycle assessment of products. Guide and backgrounds, 1992, Leiden: CML, Leiden University

[32] Bare J., TRACI 2.0: the tool for the reduction and assessment of chemical and other environmental impacts 2.0, Clean Technologies and Environmental Policy, 2011, 13(5), 687-696

[33] Goedkoop M., Spriensma R., The Eco-indicator 99 - A damage oriented method for Life Cycle Impact Assessment, 2001, Amersfoort: Pré Consultants

[34] Steen B., EPS-default valuation of environmental impacts from emission and use of resources, 1996, Swedish Environmental Protection Agency

[35] Brand G., Braunschweig A., Scheidegger A., Schwank O., Weighting in Ecobalances with the Ecoscarcity Method - Ecofactors 1997, 1998, Bern: Swiss Federal Agency for the Environment, Forests and Lanscape

[36] Jolliet O., Margni M., Charles R., Humbert S., Payet J., Rebitzer G., Rosenbaum R., IMPACT 2002+: A new life cycle impact assessment methodology, International Journal of Life Cycle Assessment, 2003, 8(6), 324-330

[37] Hauschild M.Z., Potting J., Spatial differentiation in life cycle impact assessment - the EDIP2003 methodology, 2004, Copenhagen: Danish Environmental Protection Agency

[38] Potting J., Hauschild M.Z., Spatial differentiation in life cycle impact assessment - A decade of method development to increase the environmental realism of LCIA, International Journal of Life Cycle Assessment, 2006, 11, 11-13

[39] Itsubo N., Inaba A., A new LCIA method: LIME has been completed, The International Journal of Life Cycle Assessment, 2003, 8(5), 305-305

[40] Toffoletto L., Bulle C., Godin J., Reid C., Deschenes L., LUCAS - A new LCIA method used for a Canadian-specific context, International Journal of Life Cycle Assessment, 2007, 12(2), 93-102

[41] Goedkoop M., Heijungs R., Huijbregts M., de Schryver A.M., Struijs J., van Zelm R., ReCiPe 2008: A life cycle impact assessment method which comprises harmonised category indicators at the 
midpoint and the endpoint level, 2009, Hague: Ministry of VROM

[42] Huijbregts M.A.J., Steinmann Z.J.N., Elshout P.M.F., Stam G., Verones F., Vieira M., Zijp M., Hollander A., van Zelm R., ReCiPe2016: A harmonised life cycle impact assessment method at midpoint and endpoint level, International Journal of Life Cycle Assessment, 2017, 22(2), 138-147

[43] Meteyer S., Xu X., Perry N., Zhao Y.F., Energy and material flow analysis of binder-jetting additive manufacturing processes, Procedia CIRP, 2014, 15, 19-25

[44] Kianian B., Larsson T.C., Additive manufacturing technology potential: A cleaner manufacturing alternative, In: Proceedings of the ASME 2015 International Design Engineering Technical Conferences and Computers and Information in Engineering Conference. Volume 4: 20th Design for Manufacturing and the Life Cycle Conference; 9th International Conference on Microand Nanosystems, (Boston, United States), 2015, August 2-5, Boston: The American Society of Mechanical Engineers - ASME, V004T05A001

[45] Bours J., Adzima B., Gladwin S., Cabral J., Mau S., Addressing hazardous implications of additive manufacturing: Complementing life cycle assessment with a framework for evaluating direct human health and environmental impacts, Journal of Industrial Ecology, 2017, 21, 25-36

[46] Liu Z.C., Jiang Q.H., Cong W.L., Li T., Zhang H.C., Comparative study for environmental performances of traditional manufacturing and directed energy deposition processes, International Journal of Environmental Science and Technology, 2018, 15(11), 2273-2282
[47] Drizo A., Pegna J., Environmental impacts of rapid prototyping: An overview of research to date, Rapid Prototyping Journal, 2006, 12(2), 64-71

[48] Kafara M., Suchting M., Kemnitzer J., Westermann H.H., Steinhilper R., Comparative life cycle assessment of conventional and additive manufacturing in mold core making for CFRP production, Procedia Manufacturing, 2017, 8, 223-230

[49] Faludi J., Bayley C., Bhogal S., Iribarne M., Comparing environmental impacts of additive manufacturing vs traditional machining via life-cycle assessment, Rapid Prototyping Journal, 2015, 21(1), 14-33

[50] Huang R.Z., Riddle M.E., Graziano D., Das S., Nimbalkar S., Cresko J., Masanet E., Environmental and economic implications of distributed additive manufacturing: The case of injection mold tooling, Journal of Industrial Ecology, 2017, 21, 130-143

[51] Morrow W.R., et al., Environmental aspects of laser-based and conventional tool and die manufacturing, Journal of Cleaner Production, 2007, 15(10), 932-943

[52] Agusti-Juan I., Hubert G., Environmental design guidelines for digital fabrication, Journal of Cleaner Production, 2017, 142, 27802791

[53] Cerdas F., Juraschek M., Thiede S., Herrmann C., Life cycle assessment of 3D printed products in a distributed manufacturing system, Journal of Industrial Ecology, 2017, 21, 80-93

[54] Mami F., Reveret J.P., Fallaha S., Margni M., Evaluating ecoefficiency of 3D printing in the aeronautic industry, Journal of Industrial Ecology, 2017, 21, 37-48 